\title{
$\begin{array}{ll}\text { Research Square } & \text { Preprints are preliminary reports that have not undergone peer review. } \\ \text { They should not be considered conclusive, used to inform clinical practice, } \\ \text { or referenced by the media as validated information }\end{array}$
}

\section{Tracing the Origin of Korean Invasive Populations of the Spotted Lanternfly, Lycorma Delicatula (Hemiptera: Fulgoridae)}

Hyojoong Kim ( $\sim$ hkim@kunsan.ac.kr)

Kunsan National University

\section{Sohee Kim}

Kunsan National University

\section{Yerim Lee}

Kunsan National University

Heung-Sik Lee

Animal and Plant Quarantine Agency

\section{Seong-Jin Lee}

Animal and Plant Quarantine Agency

Jong-Ho Lee

Animal and Plant Quarantine Agency

\section{Research Article}

Keywords: exotic species, invasion route, inferring origin, molecular epidemiology, population genetics, SLF

Posted Date: February 17th, 2021

DOI: https://doi.org/10.21203/rs.3.rs-199871/v1

License: (1) This work is licensed under a Creative Commons Attribution 4.0 International License. Read Full License 


\section{Abstract}

Lycorma delicatula (White) suddenly arrived in South Korea where it rapidly spread out in the central region of South Korea and became a pest causing serious damage to grapevine yards. To trace the source region of its invasiveness, population genetic structures were compared between the native region, China, and the introduced regions, Korea and Japan. We examined 762 individuals from 38 different population collections using 15 microsatellite loci. Both principal coordinate and structure analyses displayed that the Chinese populations were separated into three subgroups which were located significantly apart from each other, and, among them, Shanghai population was located closest to most Korean populations. Based on the genetic relationships and structures, although the multiple introductions into South Korea occurred at least three times, the single genetic group close to Shanghai with a high density spread was estimated to be a cause of dominant genetic structure of initial invasive populations. In addition, analysis of the approximate Bayesian computation suggested simultaneous spread from two distant locations early in the invasion by artificial transportation of the host plants including egg masses. Our population genetics study can provide a precedent case with regards to identifying unnatural spreads by anthropogenic outcomes in other invasive regions.

\section{Introduction}

The occurrence of invasive pests is considerably increasing due to a large amount of human-mediated trades around the world ${ }^{1-3}$. Sometimes an outbreak of invasive pests is a serious threat to human health, ecosystems, and the economy ${ }^{1,4,5}$. Accordingly, above all to establish their effective control strategy, determining the geographic origin of invasive pests has significant implications in many ways since many efforts are being made to control invasive pests worldwide. In particular, it is critical to figure out the biology in native regions of invasive pests to prevent reintroduction and establish a pest control plan ${ }^{6,7}$.

Lycorma delicatula (White), the spotted lanternfly (SLF) is known to be native to China, India, and Vietnam 8,9 , but after the first detected as invasive in South Korea, it was also found in Japan ${ }^{10}$ and the United States ${ }^{11}$. This species is a polyphagous sap-sucking insect, which feeds on over 100 plants worldwide, including various fruit trees (e.g. grape and stone fruits) and ornamental plants ${ }^{12}$. The SLF seriously damages the host plant by sucking phloem sap and producing honeydew, which causes sooty mold disease on leaves and this damage eventually results in an economic loss by reducing the quality and yield of the fruits ${ }^{13}$. According to a vineyard in the United States that was recently damaged by the SLF, it has shown a $90 \%$ yield loss of grapes due to the falling-off in the quality of fruits ${ }^{14}$. Furthermore, a serious infestation of SLF led to a decline in fruit production and even an effect on plant death ${ }^{14}$.

The SLF is a recent invasive pest in South Korea ${ }^{15}$. After the first detection in South Korea, it has since rapidly spread mainly in the central region of South Korea ${ }^{16,17}$. Until 2009 , this species only was found in Seoul and metropolitan areas ${ }^{15,16}$. However, this species currently distributes everywhere in mainland South Korea ${ }^{18}$. Subsequently, SLF is causing great damages to agriculture as well as wild forests in South Korea ${ }^{10,19}$. In particular, continuing outbreaks brought large damages to cultivated grapes. In the initial five 
years of the invasion, SLF damaged about one ha of vineyards, but in 2010, the damage increased to 8,478 ha ${ }^{18}$. The successful settlement of this species is thought to be due to the success of overwintering and is considered to be related to the recent increase in winter temperatures in South Korea ${ }^{17}$. Another reason why SLF could spread rapidly in South Korea has been inferred that the number of hosts available to them in South Korea is very diverse. According to the previous study, this species utilizes 41 host plants, including 38 woody and 4 herbaceous species ${ }^{16}$. In particular, the main overwintering host of SLF, the native Chinese tree, namely 'tree of heaven', Ailanthus altissima, is widely distributed in South Korea along roadsides, which allows SLF to proliferate everywhere ${ }^{17,20}$.

Sudden emergence of SLF in South Korea has so far been unknown from where they came, and unclear for how they invaded from source region to invasive region. The invasion source of the Korean SLF population has been suggested to be China $10,15,19$, but this has not been thoroughly verified. Although SLF has a wide distribution in China ${ }^{8,9}$ and is geographically close to South Korea, it is unlikely that it would have arrived across the sea since their flight ability is very poor ${ }^{21,22}$. The typical mode of dispersal of SLF is a shortdistance plant to plant flights averaging $20 \mathrm{~m}$ at a time ${ }^{21}$. Such a dispersal pattern seems not proper to fly a long-distance migration like across the sea. In Japan, this species has been recorded in Okinawa, Honshu, and Kyushu since 1930, which, however, was remarked to be sporadically observed ${ }^{23}$. Therefore, it is doubtful to be suddenly distributed in the middle part of Japan. These sudden and incomprehensible geographic distributions put weight on the assumption that the SLF was artificially transferred by exported products via transportation as adults or egg mass.

Under this assumption, a population genetic study to trace the origin of SLF has been conducted once. Kim et al. ${ }^{10}$ revealed that South Korean individuals are identical to Chinese individuals collected from Beijing, Tianjin, Qingdao, and Shanghai, based on the two mitochondrial DNA regions, NADH dehydrogenase subunit 2 and NADH dehydrogenase subunit 6 . Yet, there was a limit to the discussion of the invasion route of SLF since this study only included 18 individuals of SLF and the resolution of the two mtDNA markers have low resolution. More recently, two population genetic studies using microsatellite showed good power of discrimination on the genetic relationships between the local populations ${ }^{24,25}$. Park, et al. ${ }^{25}$ showed that there are at least three genetically distinct populations in South Korea, possibly meaning multiple introductions of SLF. Unfortunately, further discussion of the origin was not possible since there was no comparison with the source population in this study. In the results of population genetics in China ${ }^{24}$, the native region of SLF, four genetically different populations were identified. Interestingly, this study revealed that in SLF, migration was predominantly occurred by some populations rather than all populations ${ }^{24}$. However, it is not known how these characteristics relate to the SLF invading into the regions other than the place of its origin.

In this study, we addressed some questions concerning the invasion of SLF in East Asia by focusing on identifying the geographic origin and invasive route of SLF, especially weighting on the possibility of introduction from China: 1) Did the SLF come from China? 2) If SLF came from China, where did it specifically come from? 3) Has the SLF introduced South Korea several times independently? 4) Where did 
the central Japanese group come from? 5) Is there any connection with the South Korean group? Therefore, we investigated the population structure of SLF including its native region (China) and invasive regions (Japan and South Korea) using 15 microsatellite loci which were previously developed ${ }^{26}$. We characterized the genetic diversity of SLF populations from the three countries and compared the genetic differentiation among the regional populations. We also inferred the most likely source population for the Korean invasive populations by using Bayesian inference methods such as approximate Bayesian computations (ABC). Our study will facilitate to solve the correlation between the source and invasive populations of SLF, especially with regards to identifying artificial transfer possibly reoccurring in other invasive regions.

\section{Materials And Methods}

\section{SLF samples}

As all collections sampled in this study have not been carried out in restricted areas, national parks, etc. where permits are required, it is clearly stated that there is no content regarding collection permits. According to a recent study on the native distribution of SLF, this species nation-widely distributed in China and also distributed in Taiwan, Vietnam, and India where the temperature is relatively higher than in northern China ${ }^{8,9}$. SLF samples of the native area were collected from 12 localities in China (Table 1). SLF samples of the invasive area were collected from 25 localities in South Korea and one locality in Japan (Table 1). We performed dense specimen collection throughout mainland South Korea because SLF is currently distributed in almost all regions in South Korea. In total, we examined 762 individuals obtained from 38 populations. Adult and nymph samples were collected using an insect net. To avoid the chance of sampling individuals from the same hatching, each individual of SLF was collected from a single host plant (Altissima ailanthus) distantly located between the hosts. All the fresh SLF samples used for molecular analyses were preserved in 95 or $99 \%$ ethanol and stored at $-70^{\circ} \mathrm{C}$. 
Table 1

Collection data for L. delicatula analyzed for microsatellite data in this study

\begin{tabular}{|c|c|c|c|c|c|c|}
\hline Pop. ID & Country & Collection site & No. & GPS-N & GPS-E & Date \\
\hline KR06-CA & Korea & Cheonan, CN & 16 & 36.44 .01 .6 & 127.15.08.1 & 2006-09-15 \\
\hline KR07-SL & Korea & Seoul & 9 & 37.33.44.1 & 127.05.12.1 & $2007-09-26$ \\
\hline KR08-SG & Korea & Seoul \& Gyeonggi & 32 & 37.23 .52 .1 & 126.57 .26 .1 & $2008-08-20$ \\
\hline KR09-GG & Korea & Gyeonggi & 44 & 37.38.37.1 & 127.14.10.1 & $2009-07-30$ \\
\hline KR09-JE & Korea & Jeongeub, JB & 9 & 35.28 .55 .1 & 126.53 .12 .1 & 2009-09-23 \\
\hline KR09-GB & Korea & Gyeongbuk & 5 & 35.20 .22 .1 & 128.47.19.1 & $2009-07-20$ \\
\hline KR09-GW & Korea & Gangwon & 23 & 37.21 .29 .1 & 127.54.12.1 & $2009-08-24$ \\
\hline KR10-SL & Korea & Seoul & 20 & 37.33 .42 .6 & 126.56 .39 .3 & $2010-06-28$ \\
\hline KR10-IN & Korea & Incheon, GG & 40 & 37.47 .29 .9 & 126.16.14.4 & $2010-07-03$ \\
\hline KR10-NY & Korea & Namyangju, GG & 15 & 37.37.02.6 & 127.13.29.9 & $2010-08-22$ \\
\hline KR10-SW & Korea & Suwon, GG & 20 & 37.16.07.7 & 126.59 .06 .7 & 2010-08-17 \\
\hline KR10-IC & Korea & Icheon, GG & 15 & 37.20 .12 .9 & 127.26.29.5 & $2010-07-14$ \\
\hline KR10-AS & Korea & Anseong, GG & 14 & 37.04.33.1 & 127.07.57.2 & 2010-09-30 \\
\hline KR10-CA & Korea & Cheonan, CN & 22 & 36.44 .01 .6 & 127.15.08.1 & 2010-08-19 \\
\hline KR10-CY & Korea & Cheongyang, CN & 20 & 36.26 .15 .8 & 126.46 .05 .0 & 2010-09-14 \\
\hline KR10-NS & Korea & Nonsan, CN & 20 & 36.13 .20 .6 & 127.00 .55 .1 & $2010-09-29$ \\
\hline KR10-GC & Korea & Gochang, JB & 20 & 35.25 .50 .8 & 126.43.09.7 & $2010-08-20$ \\
\hline KR10-GJ & Korea & Gimje, JB & 20 & 35.48.28.7 & 126.59 .40 .7 & $2010-08-20$ \\
\hline KR10-BA & Korea & Buan, JB & 20 & 35.40 .36 .9 & 126.44 .24 .8 & $2010-08-20$ \\
\hline KR10-KJ & Korea & Gwangju, JN & 9 & 35.08 .06 .8 & 126.55 .52 .3 & 2010-09-04 \\
\hline KR10-AD & Korea & Andong, GB & 11 & 36.32.31.1 & 128.47 .49 .4 & 2010-07-31 \\
\hline KR10-YC & Korea & Yechoen, GB & 20 & 36.39 .56 .0 & 128.31.12.0 & $2010-08-06$ \\
\hline KR10-SJ & Korea & Sangju, GB & 17 & 36.22 .35 .3 & 128.08.30.7 & 2010-09-04 \\
\hline KR11-CW & Korea & Changwon, GN & 16 & 37.19 .41 .1 & 127.56.47.1 & 2011-08-05 \\
\hline KR11-SC & Korea & Samcheok, GW & 16 & 37.14 .28 .1 & 129.00 .46 .2 & $2011-06-29$ \\
\hline CN09-BJ & China & Beijing & 10 & 39.54 .16 .8 & 116.24.29.5 & $2009-07-22$ \\
\hline CN10-TJ & China & Tianjin & 16 & 39.07.15.1 & 117.12.54.1 & 2010-07-05 \\
\hline
\end{tabular}




\begin{tabular}{|lllllll|}
\hline Pop. ID & Country & Collection site & No. & GPS-N & GPS-E & Date \\
\hline CN11-YT & China & Yantai, SD & 24 & 37.31 .40 .3 & 121.21 .27 .9 & $2011-08-15$ \\
\hline CN11-HY & China & Haiyang, SD & 20 & 36.56 .59 .5 & 121.03 .28 .8 & $2011-08-16$ \\
\hline CN11-QD & China & Qingdao, SD & 24 & 36.19 .21 .6 & 120.23 .36 .9 & $2011-08-15$ \\
\hline CN11-LY & China & Linyi, SD & 20 & 35.43 .25 .9 & 118.32 .47 .1 & $2011-08-17$ \\
\hline CN11-RZ & China & Rihzhao, SD & 24 & 35.28 .44 .2 & 119.28 .15 .6 & $2011-08-16$ \\
\hline CN11-LG & China & Lianyungang, JS & 24 & 34.35 .53 .1 & 119.10 .46 .9 & $2011-08-18$ \\
\hline CN10-SH & China & Shanghai & 26 & 31.37 .23 .4 & 121.23 .50 .2 & $2010-09-04$ \\
\hline CN10-NB & China & Ningbo, ZJ & 20 & 29.47 .42 .4 & 121.47 .37 .4 & $2010-09-05$ \\
\hline CN10-TT & China & Tiantai, ZJ & 28 & 29.03 .45 .7 & 121.02 .45 .1 & $2010-09-06$ \\
\hline CN10-LA & China & Linan, ZJ & 40 & 30.14 .01 .9 & 119.43 .29 .0 & 2010-09-07 \\
\hline JP10-HS & Japan & Hakusan, IK & 13 & 36.35 .40 .8 & 136.37 .32 .1 & $2010-09-15$ \\
\hline 2. MicroSatellite genotyping & & & &
\end{tabular}

A total of 762 individuals were genotyped using 15 microsatellite loci (Lde01 to Lde15) which were previously isolated from SLF ${ }^{26}$. In a preliminary test, all loci developed in the previous study ${ }^{26}$ were polymorphic among most population samples and were included in the henceforth analyses.

Total genomic DNA was extracted from single individuals using LaboPass ${ }^{\text {TM }}$ Tissue Genomic DNA mini Kit (COSMOGENETECH, Korea) according to the manual protocol. To avoid the contamination of exotic genomic DNA (bacteria, parasites, endosymbionts, etc.), we only used muscle tissues extracted from pterothoracic parts. The muscle tissues were left in the lysis buffer with protease $K$ solution at $55^{\circ} \mathrm{C}$ for 24 hours and the cleared cuticle dehydrated. Microsatellite amplifications were performed using AccuPower ${ }^{\circledR}$ PCR PreMix K-2037 (BIONEER, Korea) in $20 \mu \mathrm{l}$ reaction mixtures containing $0.5 \mu \mathrm{M}$ forward labeled with a fluorescent dye (6-FAM, HEX, or NED), reverse primers and $0.05 \mu \mathrm{g}$ of DNA template. PCR was performed using a GS482 thermo-cycler (Gene Technologies, Essex) according to the following procedure: initial denaturation at $95^{\circ} \mathrm{C}$ for $5 \mathrm{~m}$, followed by 34 cycles of $95^{\circ} \mathrm{C}$ for 30 seconds; annealing at $56^{\circ} \mathrm{C}$ for 40 seconds; extension at $72^{\circ} \mathrm{C}$ for 45 seconds, and a final extension at $72^{\circ} \mathrm{C}$ for $5 \mathrm{~m}$. PCR products were visualized by electrophoresis on a $1.5 \%$ agarose gel with a low range DNA ladder to check for positive amplifications. Automated fluorescent fragment analyses were performed on the ABI PRISM 377 Genetic Analyzer (Applied Biosystems), and allele sizes of PCR products were calibrated using the molecular size marker, ROX labeled-size standard (GenScan ${ }^{\text {TM }}$ ROX 500, Applied Biosystems). Raw data on each fluorescent DNA products were analyzed using GeneMapper® version 4.0 (Applied Biosystems).

\section{Data analysis}


Allele data analysis results were extracted to the text file format, and then, processed in GENALEX 6.50327 through Microsoft office Excel 2013 (Microsoft). Observed $\left(H_{0}\right)$ and expected heterozygosity $\left(H_{\mathrm{E}}\right)$ values among loci were estimated using GENEPOP 4.0.7 ${ }^{28}$ among the population datasets as well as between the USA and Asian datasets. Levels of significance for Hardy-Weinberg equilibrium (HWE) and linkage disequilibrium tests were adjusted using sequential Bonferroni correction for all tests involving multiple comparisons ${ }^{29}$. Deviations from HWE were tested for heterozygote deficiency or excess. MICRO-CHECKER (Van Oosterhout) ${ }^{30}$ was used to test for null alleles ${ }^{31}$ and identify possible scoring errors because of the large-allele dropout and stuttering. The program FSTAT 2.93 was used to estimate the gene diversity $\left(H_{S}\right)$, a mean number of alleles $\left(N_{\mathrm{A}}\right)$, and allelic richness $\left(R_{\mathrm{S}}\right)$.

Groupings based on some biogeographical (spatial) and temporal groups were tested independently with analysis of molecular variance (AMOVA) ${ }^{32}$ in ARLEQUIN 3.5.1.2, with significance determined using the non-parametric permutation approach described by Excoffier, et al. ${ }^{32}$. We also used ARLEQUIN for calculations of pairwise genetic differentiation $\left(F_{\mathrm{ST}}\right)$ values ${ }^{33}$, in which 38 populations were assigned by each local collection. Exact test of population differentiation was done as optioned by 100,000 Markov chains, 10,000 Dememorisation steps, and 0.05 significance level.

To examine genetic relationships between populations of SLF, we used principal coordinate analysis (PCOA) on a genetic distance matrix based on codominant-genotypic distance ${ }^{34,35}$ provided in GENALEX $6.503^{27}$. Principal Coordinate Analysis (PCoA) is a multivariate technique that allows one to find and plot the major patterns within a multivariate data set (e.g., multiple loci and multiple samples) ${ }^{34,35}$.

The program BOTTLENECK 1.2.02 ${ }^{36}$ was used in the attempt to recognize in our samples the effect of a recent bottleneck, separately for each population. Two mutation models, considered appropriate for microsatellites ${ }^{37}$, were applied as the strictly stepwise mutational model (SMM) and the two-phase model (TPM). For the TPM, a model that includes both 90\% SMM and 10\% TPM was used for 20,000 iterations. Significant deviations in observed heterozygosity over all loci were tested using a nonparametric Wilcoxon signed-rank test ${ }^{36}$.

We performed two analyses to confirm dispersal and Isolation-by-Distance (IBD) using two different datasets of the Korean and Chinese. The Korean dataset included 17 regional populations collected only in 2010 and 2011 while the Chinese dataset consists of all 12 regional populations (Table 1). First, the level of the nation-scale spatial autocorrelation ${ }^{35,38,39}$ was analyzed. An individual-by-individual genetic distance matrix ${ }^{34,35}$ was generated along with a subsequent geographic distance matrix. The autocorrelation coefficient, $r$, is calculated through a multivariate approach (i.e., across all loci) and equals the genetic similarity between two individuals. The statistical significance of the spatial autocorrelation hypothesis is determined by generating $95 \%$ confidence intervals from 10,000 random permutations. Values of $r$ that lie within the confidence intervals fail to reject the null hypothesis of no spatial genetic structure. Restricted dispersal is suggested when $r>0$; alternatively when $r<0$, large-scale dispersal is implicated ${ }^{39}$. For further evaluation, support for the estimation of $r$ is given through the bootstrapping 
procedure. According to the geographic scale, we performed analyses at different distance size classes, ' 10 and $20 \mathrm{~km}$ ' in the Korean dataset and '20 and $40 \mathrm{~km}$ ' in the Chinese dataset, with 999 permutations and bootstrapping of $r$ with 1,000 times. Second, the significance of the regression of codominant genotypic distance (GD) on geographic distance (GGD) was tested using the Mantel procedure ${ }^{40}$, permuting 1,000 times. Spatial autocorrelation and Mantel tests were run using the program GENALEX v6.503 ${ }^{27}$. In addition, the population relative $(r)$ test, with 99 permutations for 100 bootstraps, was performed to confirmed the correlation between GD and GGD for 30 regional populations from Korea (17), China (12), and Japan (1) in GENALEX.

STRUCTURE 2.3.4 was used to analyze the genetic structure of 38 SLF populations using a Bayesian clustering approach ${ }^{41}$. We set the number of clusters $(K)$ from 1 to 11 and conducted 5 independent runs for each value of $K$. Each run consisted of a burn-in period of 30,000 steps, followed by 500,000 Markov chain Monte Carlo (MCMC) repetitions with a model allowing admixture. The $\Delta K$ value calculated as ' $\Delta K=$ $\mathrm{m}\left(\left|L^{\prime \prime}(K)\right|\right) / \mathrm{s}[L(K)]^{\prime}$ was obtained using the ad hoc quantity, which is calculated based on the second-order rate of change of the likelihood ${ }^{42}$. To correctly perform this process, $\Delta K$ was calculated using the online resource STRUCTURE HARVESTER 0.6.94 ${ }^{43}$ that explained the structure in data. Visualization of the STRUCTURE results was conducted using DISTRUCT $1.1^{44}$. In addition, GENECLASS 2 was used to perform the assignment/exclusion tests, which were used for the detection of genetic signatures of dispersal and immigration ${ }^{45}$. For each individual of population, the program estimated the probability of belonging to any other reference population or to be a resident of the population where it was sampled. The sample with the highest probability of assignment was considered as the most likely source for the assigned genotype. We used a Bayesian method of estimating pop. allele frequencies ${ }^{46}$ with Monte-Carlo resampling computation (10,000 simulated individuals) in order to infer the significance of assignments (type I error, alpha $=0.01)^{47}$.

To estimate the relative likelihood of alternative introduction scenarios of the SLF, an approximate Bayesian computation (ABC) was performed for microsatellite data as implemented in DIYABC 1.0.4 ${ }^{48}$. DIYABC allows the comparison of complex scenarios involving bottlenecks, serial or independent introductions, and genetic admixture events in introduced populations ${ }^{6}$. The parameters for modeling scenarios are the times of split or admixture events, the stable effective population size, the effective number of founders in introduced populations, the duration of the bottleneck during colonization, and the rate of admixture ${ }^{49}$. The software generates a simulated data set used to estimate the posterior distribution of parameters in order to select the most likelihood scenario ${ }^{49}$. DIYABC generates a simulated data set that is then used to select those most similar to the observed data set, and so-called selected data set $\left(n_{\delta}\right)$, which are finally used to estimate the posterior distribution of parameters ${ }^{48}$. The DIYABC 1.0 .4 analysis was conducted on the purpose of testing the initial introduction process of SLF from the source to invasive regions. Since multiple introductions were occurred based on the results of PCOA, STRUCTURE, and GENECLASS2 (see Results), several populations could be limitedly estimated as the source and invasive relationships. Therefore, the $A B C$ analyses were used to confirm the various scenarios for simulating the introduction route between the source (China) and invasive populations (Korea) which were 
selected from a large number of population collections in 2010. We set one source group (SG), Shanghai (CN10-SH), and two invasive groups, a northern invasive group (NG) of South Korea (KR10-SL, KR10-IN, KR10-SW) and a middle group (MG) of South Korea (KR10-CA, KR10-NS, KR10-BA). Four scenarios (1-4) were estimated with comparison to each other in the DIYABC (Fig S1 supplementary information). We produced 1,000,000 simulated data sets for each scenario. We used a generalized stepwise model (GSM) as the mutational model for microsatellites, which assumes increases or reductions by single repeat units 48 . To identify the posterior probability of these three scenarios, the $n_{\delta}=40,000(1 \%)$ simulated datasets closest to the pseudo-observed dataset are selected for the logistic regression, which are similar to the $n_{\delta}=$ $400(0.01 \%)$ ones for the direct approach ${ }^{49}$. The summary of statistics was calculated from the simulated and observed data for each of the tested scenarios such as the mean number of alleles per locus $(A)$, mean genetic diversity for each group and between group, genetic differentiation between pairwise groups $\left(F_{S T}\right)$, classification index, shared alleles distance $\left(D_{A S}\right)$ and Goldstein distance.

\section{Results}

\section{Genetic diversity within populations}

We successfully genotyped 762 SLF individuals using 15 microsatellite loci, which were found as all nonclonal MLGs (Table 2). Observed heterozygosity $\left(H_{0}\right)$ and expected heterozygosity $\left(H_{\mathrm{E}}\right)$ values in Korean populations ranged from 0.172 to 0.500 and from 0.171 to 0.513 , respectively, whereas $H_{\mathrm{O}}$ and $H_{\mathrm{E}}$ values ranged from 0.413 to 0.548 and from 0.423 to 0.608 , respectively, in Chinese populations. There was no evidence of significant linkage disequilibrium or frequency of null alleles. In HWE, there were significant deviations in KR09-GW, CN10-LA by heterozygote deficit, which was likely was due to retaining numerous unique genotypes with private alleles within a population related to their relatively high $H_{\mathrm{E}}$. Values related to genetic (allelic) diversity were shown as generally higher throughout the native region than in the invasive regions. Gene diversity $\left(H_{\mathrm{S}}\right)$ and mean number of alleles $\left(N_{\mathrm{A}}\right)$ in Korean populations averaged 0.45 and 3.69, respectively, which were lower than those of Chinese populations, 0.51 and 4.26 , respectively. Similarly, allelic richness $\left(R_{\mathrm{S}}\right.$, mean \pm s.d., $\left.2.63 \pm 0.31\right)$ in Korean populations were slightly lower than $R_{\mathrm{S}}$ (2.87 \pm 0.38$)$ in Chinese populations. Inbreeding coefficients $\left(F_{I S}\right)$ showed a non-significant difference between observed and expected heterozygosity in most populations, but some initial populations such as KR07-SL, KR09-GB, KR09-GW and etc. had relatively high $F_{I S}$ value in the invasive area. 
Table 2

Summary statistics for microsatellite data from 40 local populations of $L$. delicatula. observed heterozygosity $\left(H_{0}\right)$; expected heterozygosity $\left(H_{\mathrm{e}}\right)$; Hardy-Weinberg Equilibrium $(\mathrm{HWE})$; gene diversity $\left(H_{\mathrm{S}}\right)$; mean number of alleles $\left(N_{\mathrm{A}}\right)$; allelic richness $\left(R_{\mathrm{S}}\right)$. ns: non-significance in HWE $(P>0.05)$. † non-clonal multilocus genotype (MLG); * $P$ values for heterozygote deficit or heterozygote excess $(P<0.001)$; $\S F_{I S}$ multiple loci

\begin{tabular}{|c|c|c|c|c|c|c|c|c|c|}
\hline $\begin{array}{l}\text { Pop. } \\
\text { ID }\end{array}$ & MLG† & $H o( \pm$ s.d.) & $H e( \pm$ s.d.) & HWE & $\begin{array}{l}\text { HWE } \\
\text { value }\end{array}$ & $H_{S}$ & $N_{\mathrm{A}}$ & $R_{\mathrm{S}}$ & $F_{I S} \S$ \\
\hline $\begin{array}{l}\text { KR06- } \\
\text { CA }\end{array}$ & 16 & $0.443(0.073)$ & $0.495(0.059)$ & ns & 0.0001 & 0.50 & 3.67 & 2.73 & 0.109 \\
\hline $\begin{array}{l}\text { KR07- } \\
\text { SL }\end{array}$ & 9 & $0.389(0.077)$ & $0.471(0.069)$ & ns & 0.0029 & 0.48 & 3.33 & 2.81 & 0.182 \\
\hline $\begin{array}{l}\text { KR08- } \\
\text { SG }\end{array}$ & 32 & $0.388(0.061)$ & $0.445(0.058)$ & ns & 0.0012 & 0.45 & 4.42 & 2.68 & 0.130 \\
\hline $\begin{array}{l}\text { KR09- } \\
\text { GG }\end{array}$ & 44 & $0.445(0.054)$ & $0.474(0.044)$ & ns & 0.0028 & 0.47 & 5.33 & 2.79 & 0.062 \\
\hline $\begin{array}{l}\text { KR09- } \\
\text { JE }\end{array}$ & 9 & $0.398(0.069)$ & $0.404(0.066)$ & ns & 0.7114 & 0.40 & 3.17 & 2.59 & 0.014 \\
\hline $\begin{array}{l}\text { KR09- } \\
\text { GB }\end{array}$ & 5 & $0.400(0.070)$ & $0.513(0.058)$ & ns & 0.0015 & 0.53 & 2.75 & 2.75 & 0.241 \\
\hline $\begin{array}{l}\text { KR09- } \\
\text { GW }\end{array}$ & 23 & $0.322(0.066)$ & $0.401(0.074)$ & *deficit & 0.0000 & 0.40 & 3.75 & 2.55 & 0.199 \\
\hline $\begin{array}{l}\text { KR10- } \\
\text { SL }\end{array}$ & 20 & $\begin{array}{l}0.417 \\
(0.061)\end{array}$ & $\begin{array}{l}0.436 \\
(0.052)\end{array}$ & ns & 0.0373 & 0.44 & 3.92 & 2.68 & 0.046 \\
\hline $\begin{array}{l}\text { KR10- } \\
\text { IN }\end{array}$ & 40 & $\begin{array}{l}0.440 \\
(0.065)\end{array}$ & $\begin{array}{l}0.468 \\
(0.055)\end{array}$ & ns & 0.0237 & 0.47 & 4.58 & 2.80 & 0.062 \\
\hline $\begin{array}{l}\text { KR10- } \\
\text { NY }\end{array}$ & 15 & $\begin{array}{l}0.450 \\
(0.079)\end{array}$ & $\begin{array}{l}0.434 \\
(0.065)\end{array}$ & ns & 0.1189 & 0.43 & 4.17 & 2.82 & -0.039 \\
\hline $\begin{array}{l}\text { KR10- } \\
\text { SW }\end{array}$ & 20 & $\begin{array}{l}0.467 \\
(0.073)\end{array}$ & $\begin{array}{l}0.445 \\
(0.068)\end{array}$ & ns & 0.7805 & 0.44 & 4.25 & 2.77 & -0.049 \\
\hline $\begin{array}{l}\text { KR10- } \\
\text { IC }\end{array}$ & 15 & $\begin{array}{l}0.467 \\
(0.051)\end{array}$ & $\begin{array}{l}0.480 \\
(0.050)\end{array}$ & ns & 0.2636 & 0.48 & 4.00 & 2.85 & 0.029 \\
\hline $\begin{array}{l}\text { KR10- } \\
\text { AS }\end{array}$ & 14 & $\begin{array}{l}0.500 \\
(0.080)\end{array}$ & $\begin{array}{l}0.463 \\
(0.061)\end{array}$ & ns & 0.6750 & 0.46 & 3.42 & 2.68 & -0.083 \\
\hline $\begin{array}{l}\text { KR10- } \\
\text { CA }\end{array}$ & 22 & $\begin{array}{l}0.485 \\
(0.071)\end{array}$ & $\begin{array}{l}0.487 \\
(0.046)\end{array}$ & ns & 0.0214 & 0.49 & 4.08 & 2.81 & 0.004 \\
\hline $\begin{array}{l}\text { KR10- } \\
\text { CY }\end{array}$ & 20 & $\begin{array}{l}0.467 \\
(0.061)\end{array}$ & $\begin{array}{l}0.468 \\
(0.046)\end{array}$ & ns & 0.3525 & 0.47 & 4.00 & 2.80 & 0.002 \\
\hline $\begin{array}{l}\text { KR10- } \\
\text { NS }\end{array}$ & 20 & $\begin{array}{l}0.433 \\
(0.052)\end{array}$ & $\begin{array}{l}0.481 \\
(0.042)\end{array}$ & ns & 0.0001 & 0.48 & 4.58 & 2.88 & 0.101 \\
\hline
\end{tabular}




\begin{tabular}{|c|c|c|c|c|c|c|c|c|c|}
\hline $\begin{array}{l}\text { Pop. } \\
\text { ID }\end{array}$ & MLG† & $H_{0}( \pm$ s.d.) & $H e( \pm$ s.d.) & HWE & $\begin{array}{l}\text { HWE } \\
\text { value }\end{array}$ & $H_{S}$ & $N_{\mathrm{A}}$ & $R_{\mathrm{S}}$ & $F_{I S} \S$ \\
\hline $\begin{array}{l}\text { KR10- } \\
\text { GC }\end{array}$ & 20 & $\begin{array}{l}0.463 \\
(0.082)\end{array}$ & $\begin{array}{l}0.505 \\
(0.062)\end{array}$ & ns & 0.0024 & 0.51 & 4.67 & 3.01 & 0.087 \\
\hline $\begin{array}{l}\text { KR10- } \\
\text { GJ }\end{array}$ & 20 & $\begin{array}{l}0.407 \\
(0.063)\end{array}$ & $\begin{array}{l}0.437 \\
(0.063)\end{array}$ & ns & 0.4321 & 0.49 & 3.83 & 2.70 & 0.019 \\
\hline $\begin{array}{l}\text { KR10- } \\
\text { BA }\end{array}$ & 20 & $\begin{array}{l}0.442 \\
(0.060)\end{array}$ & $\begin{array}{l}0.453 \\
(0.050)\end{array}$ & ns & 0.3455 & 0.45 & 4.00 & 2.62 & 0.025 \\
\hline $\begin{array}{l}\text { KR10- } \\
\text { KJ }\end{array}$ & 9 & $\begin{array}{l}0.407 \\
(0.063)\end{array}$ & $\begin{array}{l}0.437 \\
(0.063)\end{array}$ & ns & 0.3640 & 0.44 & 3.08 & 2.59 & 0.071 \\
\hline $\begin{array}{l}\text { KR10- } \\
A D\end{array}$ & 11 & $\begin{array}{l}0.333 \\
(0.075)\end{array}$ & $\begin{array}{l}0.378 \\
(0.069)\end{array}$ & ns & 0.0438 & 0.38 & 2.50 & 2.21 & 0.124 \\
\hline $\begin{array}{l}\text { KR10- } \\
\text { YC }\end{array}$ & 20 & $\begin{array}{l}0.438 \\
(0.053)\end{array}$ & $\begin{array}{l}0.432 \\
(0.046)\end{array}$ & ns & 0.6366 & 0.43 & 3.25 & 2.45 & -0.014 \\
\hline $\begin{array}{l}\text { KR10- } \\
\text { SJ }\end{array}$ & 17 & $\begin{array}{l}0.456 \\
(0.076)\end{array}$ & $\begin{array}{l}0.444 \\
(0.048)\end{array}$ & ns & 0.7857 & 0.44 & 2.42 & 2.20 & -0.028 \\
\hline $\begin{array}{l}\text { KR10- } \\
\text { CW }\end{array}$ & 16 & $0.172(0.080)$ & $0.171(0.070)$ & ns & 0.6092 & 0.17 & 1.58 & 1.46 & -0.006 \\
\hline $\begin{array}{l}\text { KR11- } \\
\text { SC }\end{array}$ & 16 & $\begin{array}{l}0.453 \\
(0.066)\end{array}$ & $\begin{array}{l}0.447 \\
(0.063)\end{array}$ & ns & 0.8176 & 0.45 & 3.50 & 2.63 & -0.014 \\
\hline $\begin{array}{l}\text { CN09- } \\
\text { BJ }\end{array}$ & 10 & $\begin{array}{l}0.525 \\
(0.072)\end{array}$ & $\begin{array}{l}0.493 \\
(0.062)\end{array}$ & ns & 0.8788 & 0.49 & 3.58 & 2.88 & -0.068 \\
\hline $\begin{array}{l}\text { CN10- } \\
\text { TJ }\end{array}$ & 16 & $\begin{array}{l}0.432 \\
(0.085)\end{array}$ & $\begin{array}{l}0.423 \\
(0.069)\end{array}$ & ns & 0.5426 & 0.42 & 3.00 & 2.40 & -0.024 \\
\hline $\begin{array}{l}\text { CN11- } \\
\text { YT }\end{array}$ & 24 & $\begin{array}{l}0.542 \\
(0.052)\end{array}$ & $\begin{array}{l}0.558 \\
(0.028)\end{array}$ & ns & 0.0042 & 0.56 & 3.92 & 2.80 & 0.030 \\
\hline $\begin{array}{l}\text { CN11- } \\
\mathrm{HY}\end{array}$ & 20 & $\begin{array}{l}0.463 \\
(0.072)\end{array}$ & $\begin{array}{l}0.497 \\
(0.057)\end{array}$ & ns & 0.0339 & 0.50 & 3.42 & 2.56 & 0.070 \\
\hline $\begin{array}{l}\text { CN11- } \\
\text { QD }\end{array}$ & 24 & $\begin{array}{l}0.448 \\
(0.048)\end{array}$ & $\begin{array}{l}0.500 \\
(0.036)\end{array}$ & ns & 0.0138 & 0.50 & 4.08 & 2.73 & 0.106 \\
\hline $\begin{array}{l}\text { CN11- } \\
\text { LY }\end{array}$ & 20 & $\begin{array}{l}0.504 \\
(0.052)\end{array}$ & $\begin{array}{l}0.489 \\
(0.050)\end{array}$ & ns & 0.8208 & 0.49 & 3.25 & 2.62 & -0.033 \\
\hline $\begin{array}{l}\text { CN11- } \\
\text { RZ }\end{array}$ & 24 & $\begin{array}{l}0.479 \\
(0.084)\end{array}$ & $\begin{array}{l}0.457 \\
(0.076)\end{array}$ & ns & 0.7731 & 0.46 & 4.17 & 2.75 & -0.050 \\
\hline $\begin{array}{l}\text { CN11- } \\
\text { LG }\end{array}$ & 24 & $\begin{array}{l}0.424 \\
(0.051)\end{array}$ & $\begin{array}{l}0.456 \\
(0.051)\end{array}$ & ns & 0.1065 & 0.46 & 3.92 & 2.67 & 0.073 \\
\hline $\begin{array}{l}\text { CN10- } \\
\text { SH }\end{array}$ & 26 & $\begin{array}{l}0.413 \\
(0.041)\end{array}$ & $\begin{array}{l}0.477 \\
(0.048)\end{array}$ & ns & 0.0060 & 0.48 & 4.67 & 2.77 & 0.136 \\
\hline $\begin{array}{l}\text { CN10- } \\
\text { NB }\end{array}$ & 20 & $\begin{array}{l}0.479 \\
(0.065)\end{array}$ & $\begin{array}{l}0.547 \\
(0.068)\end{array}$ & ns & 0.0142 & 0.55 & 5.08 & 3.31 & 0.127 \\
\hline
\end{tabular}




\begin{tabular}{|c|c|c|c|c|c|c|c|c|c|}
\hline $\begin{array}{l}\text { Pop. } \\
\text { ID }\end{array}$ & MLG† & $H_{0}( \pm$ s.d. $)$ & $H e( \pm$ s.d.) & HWE & $\begin{array}{l}\text { HWE } \\
\text { value }\end{array}$ & $H_{S}$ & $N_{\mathrm{A}}$ & $R_{\mathrm{S}}$ & $F_{I S} \S$ \\
\hline $\begin{array}{l}\text { CN10- } \\
\text { TT }\end{array}$ & 28 & $\begin{array}{l}0.548 \\
(0.050)\end{array}$ & $\begin{array}{l}0.580 \\
(0.060)\end{array}$ & ns & 0.0216 & 0.58 & 4.83 & 3.20 & 0.058 \\
\hline $\begin{array}{l}\text { CN10- } \\
\text { LA }\end{array}$ & 40 & $\begin{array}{l}0.542 \\
(0.065)\end{array}$ & $\begin{array}{l}0.608 \\
(0.060)\end{array}$ & ${ }^{*}$ deficit & 0.0000 & 0.61 & 7.25 & 3.76 & 0.110 \\
\hline $\begin{array}{l}\text { JP10- } \\
\text { HS }\end{array}$ & 13 & $\begin{array}{l}0.436 \\
(0.060)\end{array}$ & $\begin{array}{l}0.432 \\
(0.044)\end{array}$ & ns & 0.4882 & 0.43 & 2.25 & 2.12 & -0.011 \\
\hline
\end{tabular}

\section{Genetic variation, differentiation between populations, and bottleneck}

To confirm genetic variance between the preordained groups, four cases were analyzed using AMOVA implemented in ARLEQUIN ${ }^{50}$ (Table 3). Genetic variance among groups ( $\mathrm{Va}$ ) in case 1 (grouped by year) was lowest among all cases at about $0.48 \%$, which were similarly low at about $4-6 \%$ in case 2 (grouped by country) and case 3 (grouped by year \& country). However, genetic variance among groups at about $10 \%$ in case 4 (grouped by genetic structure $(K=4)$ ) suggests that there are relatively different regional structures in combination of variation over time.

Table 3

Analysis of molecular variance (AMOVA) results for microsatellite data analysis of SLF grouped by four cases: (1) year (2) country (3) year \& country (4) genetic structure $(K=4)$

\begin{tabular}{|c|c|c|c|c|c|c|c|c|c|}
\hline \multicolumn{4}{|c|}{ Among groups } & \multicolumn{3}{|c|}{$\begin{array}{l}\text { Among populations within } \\
\text { groups }\end{array}$} & \multicolumn{3}{|c|}{ Within populations } \\
\hline Case & $\mathrm{Va}$ & Percentage & $P$ & $\mathrm{Vb}$ & Percentage & $P$ & Vc & Percentage & $P$ \\
\hline 1 & 0.02 & 0.48 & 0.3123 & 0.40 & 12.23 & $<_{0.0001}$ & 2.84 & 87.29 & $<.0001$ \\
\hline 2 & 0.14 & 4.35 & 0.0067 & 0.34 & 10.10 & $\begin{array}{l}< \\
0.0001\end{array}$ & 2.88 & 85.54 & $\begin{array}{l}< \\
0.0001\end{array}$ \\
\hline 3 & 0.20 & 6.01 & 0.0001 & 0.25 & 7.64 & $<.0001$ & 2.84 & 86.35 & $<.0001$ \\
\hline 4 & 0.33 & 9.90 & $<.0001$ & 0.19 & 5.63 & $\begin{array}{l}< \\
0.0001\end{array}$ & 2.84 & 84.47 & $<.0001$ \\
\hline
\end{tabular}

We estimated pairwise genetic differentiation $\left(F_{\mathrm{ST}}\right)$ among 38 different geographical populations (Table S1). Pairwise comparisons of $F_{\mathrm{ST}}$ values showed that Korean populations were genetically closer each other than Chinese populations. Mean $F_{\mathrm{ST}}$ within Korean populations was 0.069 , whereas mean $F_{\mathrm{ST}}$ within Chinese populations was 0.157 . $F_{\mathrm{ST}}$ between Korean and Chinese populations averaged 0.143 , while $F_{\mathrm{ST}}$ between Korean and Japanese and between Chinese and Japanese populations averaged 0.129 and 0.197, respectively. Surprisingly, $F_{\mathrm{ST}}$ values between $\mathrm{CN10-SH}$ and 13 Korean populations (KR09-JE, KR09-GB, KR09-GW, KR10-SL, KR10-IN, KR10-NY, KR10-SW, KR10-IC, KR10-AS, KR10-CA, KR10-CY, KR10-NS, KR10-GC, 
KR10-GJ, KR10-BA, and KR10-KJ) were relatively low (averaging 0.012), which was lower than $F_{\mathrm{ST}}$ within Korean populations (0.069).

A result of PCoA (Fig. 1) estimated by codominant-genotypic distance showed that the plots of the Korean populations were concentrated in the first quadrant, but ones of the Chinese populations were separated into three subgroups and located apart from each other. Interestingly, among the Chinese populations, CN10-SH was located between most Korean population plots. Within the Chinese populations, CN10-NB, CN10-LA, and CN10-TT, which were close to each other, were found to be genetically different from most other regional groups. The plot of JP10-HS was located close to those of several populations in Korea.

Although the bottleneck test should be cautiously regarded because the sample size for some populations was less than 30 individuals ${ }^{36}$, significant signatures of genetic bottlenecks using the program BOTTLENECK were tested in this study, especially for estimation of Korean and Japanese populations (Table S2). Using either the SMM and TPM, an evidence of a recent population bottleneck $(P<0.05$ for Wilcoxon signed-rank tests) was detected in 19 invasive populations (KR08-SG, KR09-GG, KR09-JE, KR09GW, KR10-SL, KR10-IN, KR10-NY, KR10-SW, KR10-IC, KR10-CA, KR10-CY, KR10-NS, KR10-GC, KR10-BA, KR10KJ, KR11-SC, CN10-SH, CN10-NB, and CN10-LA). In addition, the mode shift revealed a recent bottleneck in six invasive populations (KR07-SL, KR09-GB, KR10-KJ, KR10-SJ, KR10-CW, and JP10-HS). Only KR10-KJ was estimated to a bottleneck in both the SMM and mode shift.

\section{Spatial autocorrelation and Isolation-By-Distance}

In order to confirm the spatial distribution of each of the SLF groups in China and Korea, spatial autocorrelation was tested through spatial structure analysis by GeneAlEx 6.503. The graph of a spatial autocorrelation (Figs. S1-S4) means that the $r$ (correlation coefficient) of the Y-axis indicates that the genetically related group inferred to be distributed in a geographic boundary as the first initial section with a positive value. First, for the Korean group, the Mantel test for IBD to examine the correlation between genetic and geographic distance of the samples showed significantly lower correlation, with $r=0.078$ ( $P=$ 0.010), than for the Chinese group (see below). When GD and GGD were pairwise compared in each sample at $10 \mathrm{~km}$ class (Fig. S1) and $20 \mathrm{~km}$ class (Fig. S2), significantly positive spatial autocorrelation at distances up to ca. $80 \mathrm{~km}$, with the highest correlation coefficient within the first $10 \mathrm{~km}$ and $20 \mathrm{~km}$, respectively, was detected even though the bootstrapping of $r$ values was slightly overlapped with the $95 \%$ confidence interval of the null hypothesis at $10 \mathrm{~km}$ class. Consequently, the distribution of the SLF in Korea had IBD correlation within a spatial distribution of ca. $80 \mathrm{~km}$. This indicates that the SLF is formed of genetically related groups that show the IBD-correlated patterns within the range of about $80 \mathrm{~km}$, where both geographic and genetic differences among Korean populations is correlated. Second, for investigating the correlation between genetic and geographic distances among the Chinese samples, the Mantel test for IBD showed a positive correlation with $r=0.426(P=0.010)$. When GD and GGD were pairwise compared in each sample at $20 \mathrm{~km}$ class (Fig. S3) and 40 km class (Fig. S4), significantly positive spatial autocorrelation at distances up to ca. $260 \mathrm{~km}$ in both classes, with the highest correlation coefficient within the first or second $40 \mathrm{~km}$, respectively, was detected. Consequently, the distribution of the SLF in China was within a spatial distribution of at least ca. $260 \mathrm{~km}$, where the regional populations have been shown to be 
correlated with IBD. This indicates that the SLF is formed of genetically related groups that show genetically homogeneous patterns (similar genetic structure) in the geographic range of approximately a province-scale in China, where both geographic and genetic differences among Chinese populations is correlated. Therefore, if each SLF group is collected in a range exceeding ca. $260 \mathrm{~km}$, it would be genetically different between the groups by the geographic factor, which is strongly supported that the three SLF groups from the three regions of Beijing + Tenjin (BJ + TJ), Shandong (SD) and Zhejiang (ZJ) are genetically different groups. In addition, the population relative test was tested to confirm the correlation of IBD in each population using GeneAIEx 6.503.

The population relative test can be used to show the ideal IBD correlation when the genetic distances of one group vs. all other groups are positively correlated each other; that is, when the $r$ value is significantly large (Fig. 2). In contrast, there is a high probability that it was either a source or invasive site (Fig. 2) if the I value is very small when the correlation compared between the origin and invasion sites. Therefore, CN10$\mathrm{SH}$ with the smallest $r$ value in the origin area is highly likely to be the source population in China, and KR10-NS with the smallest $r$ value in the invasive area is highly likely to be the initial invasive population in Korea (Fig. 2), which is a similar concept in application of the correlation between GD and GGD for tracing the origin of invasive pest previously studied by Lozier, et al. ${ }^{51}$.

\section{Genetic structure and assignment}

In the STRUCTURE analyses, the most likely number of clusters was $K=2$ using the $\Delta K$ calculation from $K$ $=1$ to $K=11^{42}$. However, Evanno, et al. ${ }^{42}$ had emphasized that while $\Delta K$ was useful in identifying the correct number of clusters and that it should be used together with the battery of other information provided by STRUCTURE. Thus, we decided that the results of STRUCTURE analyses were demonstrated when $K=2,3,4,5$ with considering both $L(K)$ and $\Delta K$. In the all STRUCTURE results $(K=2,3,4,5$; Figs. S5, S6), CN10-NB + CN10-TT + CN10-LA had a dominant 'pink' assignment. The genetic structure when $K=3,4$ resulted in that most of Korean populations and CN10-SH indicated similar pattern of assignments having more dominant 'white' while KR11-SC and the Chinese populations collected in 2011 showed mixed but more dominant 'blue.' The genetic structure when $K=5$ (Fig. 3) displayed that CN09-BJ, CN10-TJ, and JP10HS had a similar dominant 'green' assignment while KR10-AD and KR10-CW had a dominant 'red' assignment.

The Bayesian assignment tests using GENECLASS 2 were carried out to identify population membership of individuals from all populations (Table S3). The result of the assignment test indicated the average probability with which individuals were assigned to the corresponding reference population. The selfassignment probability values averaged $0.380 \pm 0.07$ (mean \pm s.d.) in Korean populations, and $0.525 \pm 0.03$ in Chinese populations. This assignment approach also could be used to interpret the inference of invasion of SLF genotypes into Korea from China. From Chinese to Korean populations, assignment probability values averaged $0.116 \pm 0.118$. Similar to the results of STRUCTURE (Fig. 3), among Chinese populations, $\mathrm{CN} 10-\mathrm{SH}$ had the highest assignment probability values averaging $0.337 \pm 0.112$ from most Korean populations. 


\section{Inferring an invasive route by testing hypothetical scenarios by $\mathrm{ABC}$ analysis}

To propose the most likelihood scenario of an invasive route of the SLF when introduced into Korea, ABC tests were conducted with four scenarios (Fig. S7). The dataset included three different groups as one source group (SG) and two invasive groups (NG, MG) (see M\&M). These results were presented as a logistic regression using DIYABC software, estimating the posterior probability of each tested evolutionary scenarios of invasion for the selected simulated data $\left(n_{\delta}\right)^{48}$, which ranged between 4,000 and $40,000 n_{\delta}$.

As the results (Fig. S8), scenario 1 obtained the highest posterior probability ranging from $0.021\left(n_{\delta}=\right.$ $4,000)$ to $0.036\left(n_{\delta}=40,000\right)$ with a $95 \% \mathrm{Cl}$ of $0.006-0.036$ and $0.028-0.043$, which assumes NG recently diverged from MG and both previously diverged from SG. Scenario 2, which assumes MG recently diverged from NG and both previously diverged from SG, showed a posterior probability ranging from $0.019\left(n_{\delta}=\right.$ $4,000)$ to $0.035\left(n_{\delta}=40,000\right)$ with a $95 \% \mathrm{Cl}$ of $0.006-0.032$ and $0.028-0.043$. Scenario 3 , which assumes MG recently diverged from $S G$ and $N G$ previously diverged from $S G$, showed a posterior probability ranging from $0.028\left(n_{\delta}=4,000\right)$ to $0.047\left(n_{\delta}=40,000\right)$ with a $95 \% \mathrm{Cl}$ of $0.010-0.047$ and $0.024-0.036$. Scenario 4 , which assumes MG and NG simultaneously diverged from SG when introducing, showed a posterior probability ranging from $0.932\left(n_{\delta}=4,000\right)$ to $0.900\left(n_{\delta}=40,000\right)$ with a $95 \% \mathrm{Cl}$ of $0.904-0.961$ and $0.886-0.914$.

The $A B C$ simulations based on the four alternative scenarios $(1,2,3,4)$ for tracing the invasion route of the SLF gave strong support to the scenario 4 (mean posterior probability: $0.900-0.932$ ) while the remaining other three scenarios $(1,2,3)$ showed much lower posterior probabilities $(<0.036 ;$ Fig. S8). These suggest that scenario 4 appeared as the most robust hypothesis, presenting the highest posterior probability among the four scenarios tested.

\section{Discussion}

\section{Genetic structures of SLF in the native and invasive areas}

Our results provide a well resolved genetic structure of SLF in its native and invasive regions. We confirmed that there are three subgroups, 'BJ + TJ' (Subgroup 1), 'SD + JS + SH' (Subgroup 2), and 'ZJ' (Subgroup3), in the native population (Figs. 1, 3). Our results are consistent with the previous finding that SLF shows genetic differences in the north and south of the Yangtze River rather than geographic distance ${ }^{24}$. The subgroup $2(\mathrm{SD}+\mathrm{JS}+\mathrm{SH})$ and subgroup $3(\mathrm{ZJ})$ are geographically separated each other by the Yangtze River; that is, it seems to be the restriction of gene flow. In addition, significant genetic differences among the subgroups based on geographic isolation are very consistent with the former results showing significant morphological differences in wings in the morphometric analysis ${ }^{19}$. Zhang, et al. ${ }^{24}$ revealed that the Chinese SLF population is divided into four subgroups, including three subgroups in the north of the Yangtze River and one subgroup in the south of the Yangtze River. Similar to the previous studies ${ }^{10,24}$, 
it is accordant with that the SLF populations were divided into several subgroups by the Yangtze River and east-west boundaries in China. However, since our sampling did not cover the western China subgroup (i.e. Shaanxi and Gansu) ${ }^{24}$, only three subgroups were identified (Figs. 1,3 ).

The Korean and Japanese populations showed relatively low genetic diversity, a typical low genetic diversity in the invasive populations ${ }^{51-53}$. Accordingly, genetic bottlenecks were rarely found in the native region, but most of the populations in Korea were found to have genetic drift due to the founder effect of the early invasive population (Table S2). In the Korean SLF population, it could be confirmed that traces of simple genotype distribution of the SLF population over a wide area to spread and impact of outbreaks caused by anthropogenic factors such as transportation in the short period from the invasion process. The genotype of most of the samples spread predominantly in Korea was similar to that of CN10-SH sampled in Shanghai, China. In Korea, compared to the large area in which SLF was distributed, the genetic diversity was relatively low and there was no significant genetic difference according to geographic distance or based on IBD correlation. In contrast, JP10-HS found initially in Japan was genetically close to CN09-BJ and CN10-TJ in China (Fig. 3; Table S1). These results are evidence to support the spread of SLF in East Asia by artificial routes from remote regions rather than natural migrants between geographically close regions.

Based on the results of our population genetics (Figs. 1, 3, S5, S6), most of the populations that invaded and spread to Korea were found to be genetically very similar to subgroup $2(\mathrm{SD}+\mathrm{JS}+\mathrm{SH})$ in China. In Korea, the genetic structure of the samples collected in 2006-2007 was more or less different from the dominant structure of those collected in 2010-2011. The populations collected from 2008 to 2011 in Korea were very similar to CN10-SH except for KR11-SC which, however, was closer to the Shandong group (e.g. CN11-YT, CN11-HY). Overall, most of the SLF populations in Korea appear to have introduced and spread from Shanghai (CN10-SH) while certain populations have independently and intermittently settled in several regions (e.g. KR11-CW, KR11-SC). Similar to our results, the populations sampled in the previous population genetic study of SLF in Korea did not show significant genetic differences between regions except Samcheok ${ }^{25}$. On the other hand, in the early invasion group, traces of variation due to inland genetic drift were found in the populations such as KR10-AD, KR10-YC, and KR10-SJ. However, in most other regions, the single genetic group close to $\mathrm{CN10-SH}$ with a high initial density spread during the multiple introduction process (at least three times) was found to be a cause of forming a relatively simple and dominant genetic structure throughout Korea.

\section{Spatial distribution of SLF between origin and invasion areas}

Based on the results of the spatial autocorrelation (Figs. S1-S4) and IBD, SLF is considered a species with very limited migration and spread in natural ecosystems. In China, the geographical structure of spatial distribution of SLF indicated that the genetically related group were formed within about $260 \mathrm{~km}$ in the source area (Figs. S3, S4). As can be seen from the isolation between the Yangtze River, there were topographical elements that could lead the restriction of gene flow under natural conditions (mountain range, river, etc.) supporting that SLF is not a voracious migratory insect ${ }^{21}$. In the early days of the invasion, it was argued that the SLF was introduced by airflow from China to Korea by flight, but it was 
estimated that flight invasion would be impossible due to the poor flight capability ${ }^{21}$. The three subgroups of China shown in this study show that gene flow is limited by spatial distribution and that each subgroup is significantly differentiated by geographic isolation. On the other hand, Korea, which is an invasion area, has a smaller space than China and is not far from the first invasion spot(s) to the spread area. The prevalence SLF group in 2010 and 2011, which is presumed to have been simultaneously invaded and spread from Shanghai to northern and central Korea by $A B C$ analysis estimates, spread in a relatively smaller spatial distribution than the origin, and it was found to be not IBD-correlated by the spatial autocorrelation results (Figs. S1, S2).

For the SLF to settle and re-spread, the host plant is most essentially limited to the overwintering host, especially Ailanthus altissima, so it seems likely that the settling and spread pattern will repeat advantageously around the zone where the host plants were densely cultivated ${ }^{20,54}$. Tree of heaven, $A$. altissima, is commonly used for ornamental landscape trees, street trees, and embankments in China and Korea, so it is pointed out that its high density in the invasive range has been a major cause of the spread of SLF ${ }^{13}$. Interestingly, this species tends to show host preference for various plants for feeding during the nymph period after emerging, as a generalist, but an overwintering host plant such as $A$. alitissima is essential for lay eggs after mating ${ }^{20}$. As the ecological feature of SLF is overwintering through egg masses on the surface of host plants or even artifacts, the artificial spread is possible through vehicle transport as in the case of the spread of boll weevils in the United States ${ }^{55}$. As with the recent prediction model study ${ }^{18}$, spatial distribution and spread of SLF in Korea are closely related to anthropogenic factors (i.e. human footprint). The prevalence of the initial population seen in the results of the MAXENT analyses

18 was relatively high by the human footprint including transporting activity although it was not a naturally environmental variable. Because of these artificial factors, the rapid spread and spatial distribution of SLF would have been possible despite a short period of invasion, so it is supported that IBD correlation was not significant in Korea in our results.

\section{Introduction process of SLF from China}

Our results suggest that some populations of SLF in around 2009 have been introduced independently and intermittently into Korea and, after then, certain populations that appeared to dominate the genetic structure in $\mathbf{2 0 1 0}$ had a large spread around that time. At the beginning of the invasion, the insignificant genetic differences and the significance of the bottleneck in the Korean populations support the rapid spread of a certain source population with high initial density. Most of the SLF populations dominantly found in Korea was the result of the spread of individuals native to Shanghai, but apart from these, genetically similar individuals to Beijing and Tianjin were in Cheonan in 2006 (similar to the 2010 Japanese population), and those matching the Shandong region appear to have been found in Samcheok in 2011. Interestingly, considering that similar genotypes were occurring nationwide in Korea in 2010 and 2011, it is not possible to rule out continuous introductions from China, especially Shanghai, to South Korea by the bridgehead effect ${ }^{56}$ rather than the re-proliferation of populations that initially entered Korea. In conclusion, it was estimated that the SLF populations multiply introduced into Korea had at least three independent introductions (in 2006, in 2007-2011, in 2011). 
The situation of the SLF introduction in Korea was estimated as the import of the seedlings of $A$. alitissima, the main host plant of SLF, and it is very relevant to the initial spread that the seedlings incorporating SLF's egg masses were imported in large quantities at that time ${ }^{13,15}$. As a result of performing the $A B C$ analysis, the initial spread of dominant groups (similar to Shanghai) spread to Korea collected in 2010 and 2011 did not consist of sequential geographic paths in Korea. In other words, it seems that their spread was not a step-by-step spread that occurs naturally by migration, but that it occurred simultaneously in two places in the north and the middle of South Korea by artificial transportation, i.e. hitchhiking ${ }^{57,58}$. Initially, a certain group very similar to the population in the Chongming Island area in Shanghai, where CN10-SH were collected, predominantly spread throughout Korea. The area surveyed in Shanghai was an artificial reforestation area of Chongming Island, planted for landscaping, with many traces of egg mass, and high habitat density (Fig. 4). In addition, the Shanghai population was believed to have moved more north in latitude, which is more genetically close to the groups of the geographically distant Shandong and Jiangsu rather than that of the geographically close Zhejiang. The spread of SLF seems to be evidence of human intervention, and in fact, $A$. altissima seedlings were brought into Korea and divided into a nursery in one place (communication with Animal Plant Quarantine Agency, Korea). The seedlings were transported to geographically distant regions in Korea, and the spread of the SLF introduced as a form of the egg mass was a cause that could occur simultaneously ${ }^{13,20}$. This initial spread process of this SLF exactly corresponded with the results of $A B C$ analysis.

Population genetics study of this invasion propagation process may be necessary for regions where SLF has invaded, particularly in North America because it can help identify unnatural spreads that are anthropogenic outcomes ${ }^{57}$. Their ecological characteristics are those that do not appear in the native area and have the characteristic of being explosively spread out in the invasion region. As in Korea, certain genetically simple groups have spread throughout the country despite having a bottleneck. This mostly seems to be the distribution of egg masses through the transport of host plants or artifacts affected by hitchhiking ${ }^{58}$, so identifying the movement or distribution of host plants can help to track their dispersion process in combination with the population genetics approach.

\section{Declarations}

\section{Acknowledgements}

This research was supported by a grant from the Korea Environment Industry \& Technology Institute (KEITI) through Exotic Invasive Species Management Program (2018002270005), funded by Korea Ministry of Environment (MOE). It was also supported by Basic Science Research Program through the National Research Foundation of Korea (NRF) funded by the Ministry of Education (NRF-2018R1D1A3B07044298). This research was also supported by a fund (Project Code No. PQ20161B042) by Research of Animal and Plant Quarantine Agency, South Korea.

\section{Author contributions}


H.K.: conceptualization, fund acquisition, project supervision, sample collection, methodology, data curation, data analysis, writing-original manuscript, writing-review and editing. S.K.: methodology, data curation, data analysis, writing-original manuscript, writing-review and editing. Y.L.: conceptualization, sample collection, methodology, data curation, writing-original manuscript, writing-review and editing. H.L., S.L., J.L.: sample collection, writing-review and editing. All authors agreed and approved the final manuscript.

\section{Competing interests}

The authors declare no competing interests.

\section{References}

1. Hulme, P. Trade, transport and trouble: Managing invasive species pathways in an era of globalization. Journal of Applied Ecology 46, 10-18, doi:10.1111/j.1365-2664.2008.01600.x (2009).

2. Peakall, R., Ruibal, M., Lindenmayer, D. B., SPATIAL AUTOCORRELATION ANALYSIS \& OFFERS NEW INSIGHTS INTO GENE FLOW IN THE AUSTRALIAN BUSH RAT. RATTUS FUSCIPES. Evolution. 57, 11821195 https://doi.org/10.1111/j.0014-3820.2003.tb00327.x (2003).

3. Mantel, N. The detection of disease clustering and a generalized regression approach. Cancer research. 27, 209-220 (1967).

4. Pritchard, J. K., Stephens, M. \& Donnelly, P. Inference of population structure using multilocus genotype data. Genetics. 155, 945-959 (2000).

5. Evanno, G., Regnaut, S. \& Goudet, J. Detecting the number of clusters of individuals using the software STRUCTURE: a simulation study. Molecular ecology. 14, 2611-2620 (2005).

6. Earl, D. A. STRUCTURE HARVESTER: a website and program for visualizing STRUCTURE output and implementing the Evanno method. Conservation genetics resources. 4, 359-361 (2012).

7. Rosenberg, N. A. DISTRUCT: a program for the graphical display of population structure. Mol. Ecol. Resour. 4, 137-138 (2004).

8. Piry, S. et al. GENECLASS2: a software for genetic assignment and first-generation migrant detection. $J$ Hered. 95, 536-539 (2004).

9. Rannala, B. \& Mountain, J. L. Detecting immigration by using multilocus genotypes. Proceedings of the National Academy of Sciences 94, 9197-9201(1997).

10. Paetkau, D., Slade, R., Burden, M. \& Estoup, A. Genetic assignment methods for the direct, real-time estimation of migration rate: a simulation-based exploration of accuracy and power. Mol. Ecol. 13, 5565 https://doi.org/10.1046/j.1365-294X.2004.02008.x (2004).

11. Cornuet, J. M. et al. Inferring population history with DIY ABC: a user-friendly approach to approximate Bayesian computation. Bioinformatics. 24, 2713-2719 https://doi.org/10.1093/bioinformatics/btn514 (2008). 
12. Cornuet, J. M., Ravigne, V. \& Estoup, A. Inference on population history and model checking using DNA sequence and microsatellite data with the software DIYABC (v1.0). BMC Bioinform. 11, https://doi.org/10.1186/1471-2105-11-401 (2010).

13. Excoffier, L., Laval, G. \& Schneider, S. Arlequin (version 3.0): An integrated software package for population genetics data analysis. Evol Bioinform. 1, 47-50 (2005).

14. Lozier, J. D., Roderick, G. K. \& Mills, N. J. Tracing the invasion history of mealy plum aphid, Hyalopterus pruni (Hemiptera: Aphididae), in North America: a population genetics approach. Biol Invasions. 11, 299-314 https://doi.org/10.1007/s10530-008-9248-8 (2009).

15. Kim, H., Hoelmer, K. A. \& Lee, S. Population genetics of the soybean aphid in North America and East Asia: test for introduction between native and introduced populations. Biol Invasions. 19, 597-614 https://doi.org/10.1007/s10530-016-1299-7 (2017).

16. Zepeda-Paulo, F. A. et al. The invasion route for an insect pest species: the tobacco aphid in the New World. Mol. Ecol. 19, 4738-4752 https://doi.org/10.1111/j.1365-294X.2010.04857.x (2010).

17. Kim, I. K., Koh, S. H., Lee, J. S., Choi, I., Shin, S. C. \& W. \& Discovery of an egg parasitoid of Lycorma delicatula (Hemiptera: Fulgoridae) an invasive species in South Korea. Journal of Asia-Pacific Entomology. 14, 213-215 https://doi.org/10.1016/j.aspen.2011.01.004 (2011).

18. Kim, K. S., Sappington, T. W. \& Allen, C. T. Genetic profiling to determine potential origins of boll weevils (Coleoptera: Curculionidae) captured in a Texas eradication zone: endemicity, immigration, or sabotage? Journal of economic entomology. 101, 1729-1736 https://doi.org/10.1603/0022-0493101.6.1729 (2008).

19. Ascunce, M. S. et al. Global Invasion History of the Fire Ant Solenopsis invicta. Science. 331, 10661068 https://doi.org/10.1126/science.1198734 (2011).

20. Keller, J. A. et al. Dispersal of Lycorma delicatula (Hemiptera: Fulgoridae) Nymphs Through Contiguous. Deciduous Forest. 49, 1012-1018 (2020).

21. Gippet, J. M. W., Liebhold, A. M., Fenn-Moltu, G. \& Bertelsmeier, C. Human-mediated dispersal in insects. Current Opinion in Insect Science. 35, 96-102 https://doi.org/10.1016/j.cois.2019.07.005 (2019).

22. 22. Leach, A. \& Leach, H. Characterizing the spatial distributions of spotted lanternfly (Hemiptera: Fulgoridae) in Pennsylvania vineyards. Scientific Reports 10, 20588, doi:10.1038/s41598-020-77461-9 (2020).

23. 23. Tadauchi, O. \& Inoue, H. On MOKUROKU file based on "A Check List of Japanese Insects" on INTERNET. ESAKIA 40, 81-84 (2000).

24. 24. Zhang, L., Zhao, W., Wang, F.-p. \& Qin, D. Genetic Diversity and Population Structure of Natural Lycorma delicatula (White) (Hemiptera: Fulgoridea) Populations in China as Revealed by Microsatellite and Mitochondrial Markers. Insects 10 (2019).

25. 25. Park, M., Kim, K.-S. \& Lee, J.-H. Genetic structure of Lycorma delicatula (Hemiptera: Fulgoridae) populations in Korea: implication for invasion processes in heterogeneous landscapes. Bulletin of Entomological Research 103, 414-424, doi:10.1017/S0007485313000011 (2013). 
26. 26. Kim, H. et al. Development and characterization of 15 microsatellite loci from Lycorma delicatula (Hemiptera: Fulgoridae). Anim Cells Syst 15, 295-300, doi:Doi 10.1080/19768354.2011.604936 (2011).

27. 27. Peakall, R. \& Smouse, P. E. GenAlEx 6.5: genetic analysis in Excel. Population genetic software for teaching and research-an update. Bioinformatics 28, 2537-2539, doi:10.1093/bioinformatics/bts460 (2012).

28. 28. Raymond, M. \& Rousset, F. Genepop (Version-1.2) - Population-Genetics Software for Exact Tests and Ecumenicism. $J$ Hered 86, 248-249 (1995).

29. 29. Rice, W. R. Analyzing Tables of Statistical Tests. Evolution 43, 223-225, doi:10.2307/2409177 (1989).

30. 30. Oosterhout, C. v., Hutchinson, W. F., Wills, D. P. M. \& Shipley, P. micro-checker: software for identifying and correcting genotyping errors in microsatellite data. Molecular Ecology Notes 4, 535538 (2004).

31. 31. Brookfield, J. F. Y. A simple new method for estimating null allele frequency from heterozygote deficiency. Molecular Ecology 5, 453-455, doi:10.1046/j.1365-294X.1996.00098.x (1996).

32. 32. Excoffier, L., Smouse, P. E. \& Quattro, J. M. Analysis of molecular variance inferred from metric distances among DNA haplotypes: application to human mitochondrial DNA restriction data. Genetics 131, 479-491 (1992).

33. 33. Weir, B. S. \& Cockerham, C. C. Estimating F-Statistics for the Analysis of Population Structure. Evolution 38, 1358-1370, doi:10.2307/2408641 (1984).

34. 34. Peakall, R., Smouse, P. E. \& Huff, D. R. Evolutionary implications of allozyme and RAPD variation in diploid populations of dioecious buffalograss Buchloë dactyloides. Molecular Ecology 4, 135-148, doi:10.1111/j.1365-294X.1995.tb00203.x (1995).

35. 35. Smouse, P. E. \& Peakall, R. Spatial autocorrelation analysis of individual multiallele and multilocus genetic structure. Heredity 82, 561-573, doi:10.1038/sj.hdy.6885180 (1999).

36. 36. Cornuet, J. M. \& Luikart, G. Description and power analysis of two tests for detecting recent population bottlenecks from allele frequency data. Genetics 144, 2001-2014 (1996).

37. 37. Piry, S., Luikart, G. \& Cornuet, J. M. BOTTLENECK: A computer program for detecting recent reductions in the effective population size using allele frequency data. $J$ Hered $90,502-503$, doi:DOI 10.1093/jhered/90.4.502 (1999).

38. 38. Double, M. C., Peakall, R., Beck, N. R. \& Cockburn, A. DISPERSAL, PHILOPATRY, AND INFIDELITY: DISSECTING LOCAL GENETIC STRUCTURE IN SUPERB FAIRY-WRENS (< span class="genusspecies">MALURUS CYANEUS</span>). Evolution 59, 625-635, 611 (2005).

39. 39. Peakall, R., Ruibal, M. \& Lindenmayer, D. B. SPATIAL AUTOCORRELATION ANALYSIS OFFERS NEW INSIGHTS INTO GENE FLOW IN THE AUSTRALIAN BUSH RAT, RATTUS FUSCIPES. Evolution 57, 11821195, doi:10.1111/j.0014-3820.2003.tb00327.x (2003).

40. 40. Mantel, N. The detection of disease clustering and a generalized regression approach. Cancer research 27, 209-220 (1967). 
41. 41. Pritchard, J. K., Stephens, M. \& Donnelly, P. Inference of population structure using multilocus genotype data. Genetics 155, 945-959 (2000).

42. 42. Evanno, G., Regnaut, S. \& Goudet, J. Detecting the number of clusters of individuals using the software STRUCTURE: a simulation study. Molecular ecology 14, 2611-2620 (2005).

43. 43. Earl, D. A. STRUCTURE HARVESTER: a website and program for visualizing STRUCTURE output and implementing the Evanno method. Conservation genetics resources 4, 359-361 (2012).

44. 44. Rosenberg, N. A. DISTRUCT: a program for the graphical display of population structure. Mol. Ecol. Resour. 4, 137-138 (2004).

45. 45. Piry, S. et al. GENECLASS2: a software for genetic assignment and first-generation migrant detection. J Hered 95, 536-539 (2004).

46. 46. Rannala, B. \& Mountain, J. L. Detecting immigration by using multilocus genotypes. Proceedings of the National Academy of Sciences 94, 9197-9201 (1997).

47. 47. Paetkau, D., Slade, R., Burden, M. \& Estoup, A. Genetic assignment methods for the direct, real-time estimation of migration rate: a simulation-based exploration of accuracy and power. Molecular Ecology 13, 55-65, doi:DOI 10.1046/j.1365-294X.2004.02008.x (2004).

48. 48. Cornuet, J. M. et al. Inferring population history with DIY ABC: a user-friendly approach to approximate Bayesian computation. Bioinformatics 24, 2713-2719, doi:DOI 10.1093/bioinformatics/btn514 (2008).

49. 49. Cornuet, J. M., Ravigne, V. \& Estoup, A. Inference on population history and model checking using DNA sequence and microsatellite data with the software DIYABC (v1.0). Bmc Bioinformatics 11, doi:Doi 10.1186/1471-2105-11-401 (2010).

50. 50. Excoffier, L., Laval, G. \& Schneider, S. Arlequin (version 3.0): An integrated software package for population genetics data analysis. Evol Bioinform 1, 47-50 (2005).

51. 51. Lozier, J. D., Roderick, G. K. \& Mills, N. J. Tracing the invasion history of mealy plum aphid, Hyalopterus pruni (Hemiptera: Aphididae), in North America: a population genetics approach. Biol Invasions 11, 299-314, doi:DOI 10.1007/s10530-008-9248-8 (2009).

52. 52. Kim, H., Hoelmer, K. A. \& Lee, S. Population genetics of the soybean aphid in North America and East Asia: test for introduction between native and introduced populations. Biol Invasions 19, 597614, doi:10.1007/s10530-016-1299-7 (2017).

53. 53. Zepeda-Paulo, F. A. et al. The invasion route for an insect pest species: the tobacco aphid in the New World. Molecular Ecology 19, 4738-4752, doi:DOI 10.1111/j.1365-294X.2010.04857.x (2010).

54. 54. Kim, I. K., Koh, S. H., Lee, J. S., II Choi, W. \& Shin, S. C. Discovery of an egg parasitoid of Lycorma delicatula (Hemiptera: Fulgoridae) an invasive species in South Korea. Journal of Asia-Pacific Entomology 14, 213-215, doi:DOI 10.1016/j.aspen.2011.01.004 (2011).

55. 55. Kim, K. S., Sappington, T. W. \& Allen, C. T. Genetic profiling to determine potential origins of boll weevils (Coleoptera: Curculionidae) captured in a Texas eradication zone: endemicity, immigration, or sabotage? Journal of economic entomology 101, 1729-1736, doi:10.1603/0022-0493-101.6.1729 (2008). 
56. 56. Ascunce, M. S. et al. Global Invasion History of the Fire Ant Solenopsis invicta. Science 331, 10661068, doi:10.1126/science.1198734 (2011).

57. 57. Keller, J. A. et al. Dispersal of Lycorma delicatula (Hemiptera: Fulgoridae) Nymphs Through Contiguous, Deciduous Forest. 49, 1012-1018 (2020).

58. 58. Gippet, J. M. W., Liebhold, A. M., Fenn-Moltu, G. \& Bertelsmeier, C. Human-mediated dispersal in insects. Current Opinion in Insect Science 35, 96-102, doi:https://doi.org/10.1016/j.cois.2019.07.005 (2019).

\section{Figures}

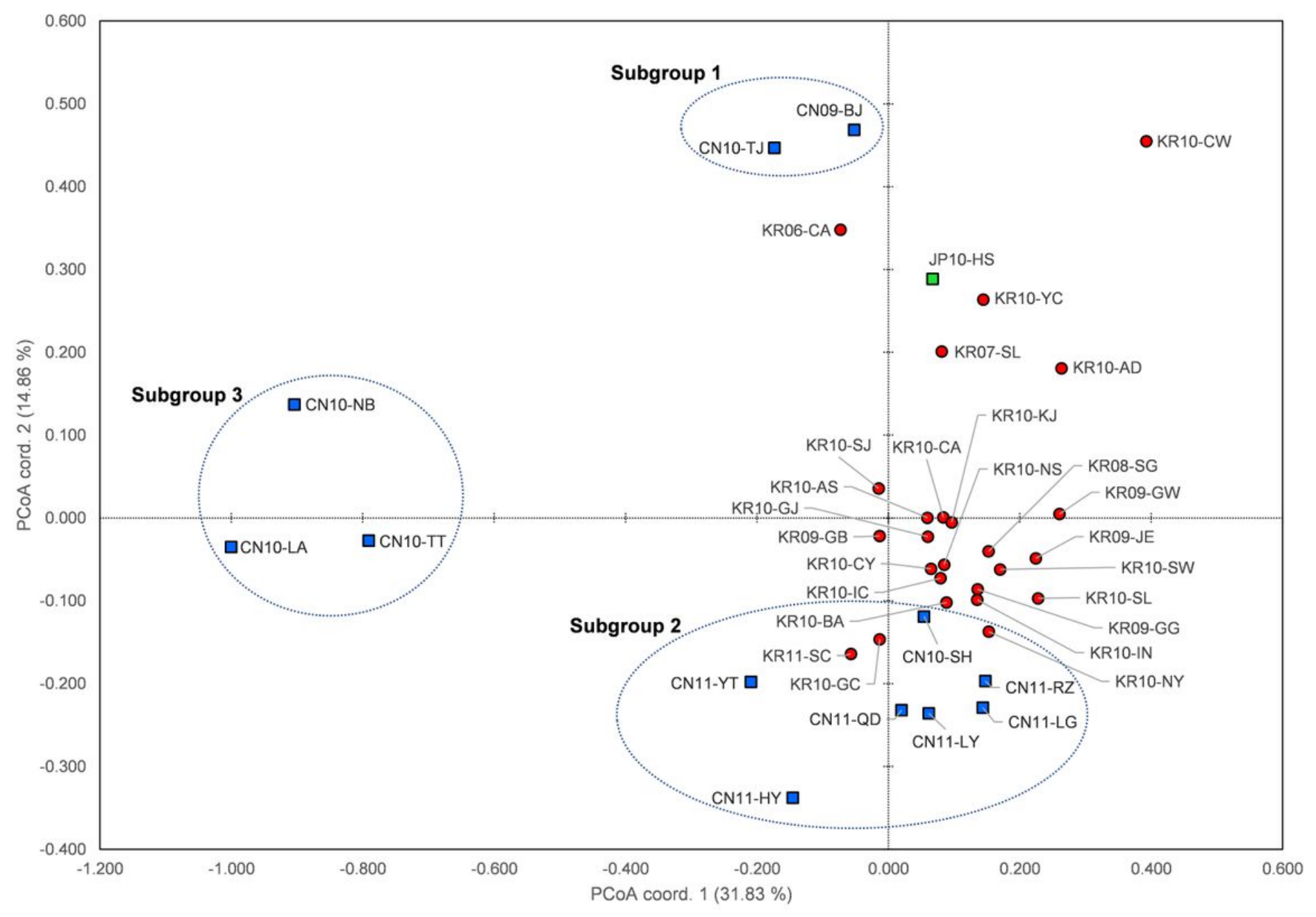

\section{Figure 1}

A plot of the principal coordinate analysis based on the first two factors for 38 populations of SLF in GENALEX. Each color corresponds to the countries; red - Korea with 25 populations; blue - China with 12 populations; green - Japan with 1 population. 




Figure 2

Population relative ( $r$ ) test for 30 regional populations from Korea (17), China (12), and Japan (1) in GENALEX. r (blue) means autocorrelation coefficient, U (upper red) $+95 \%$ confidence, L (lower red) $-95 \%$ confidence, cross bars standard deviation.

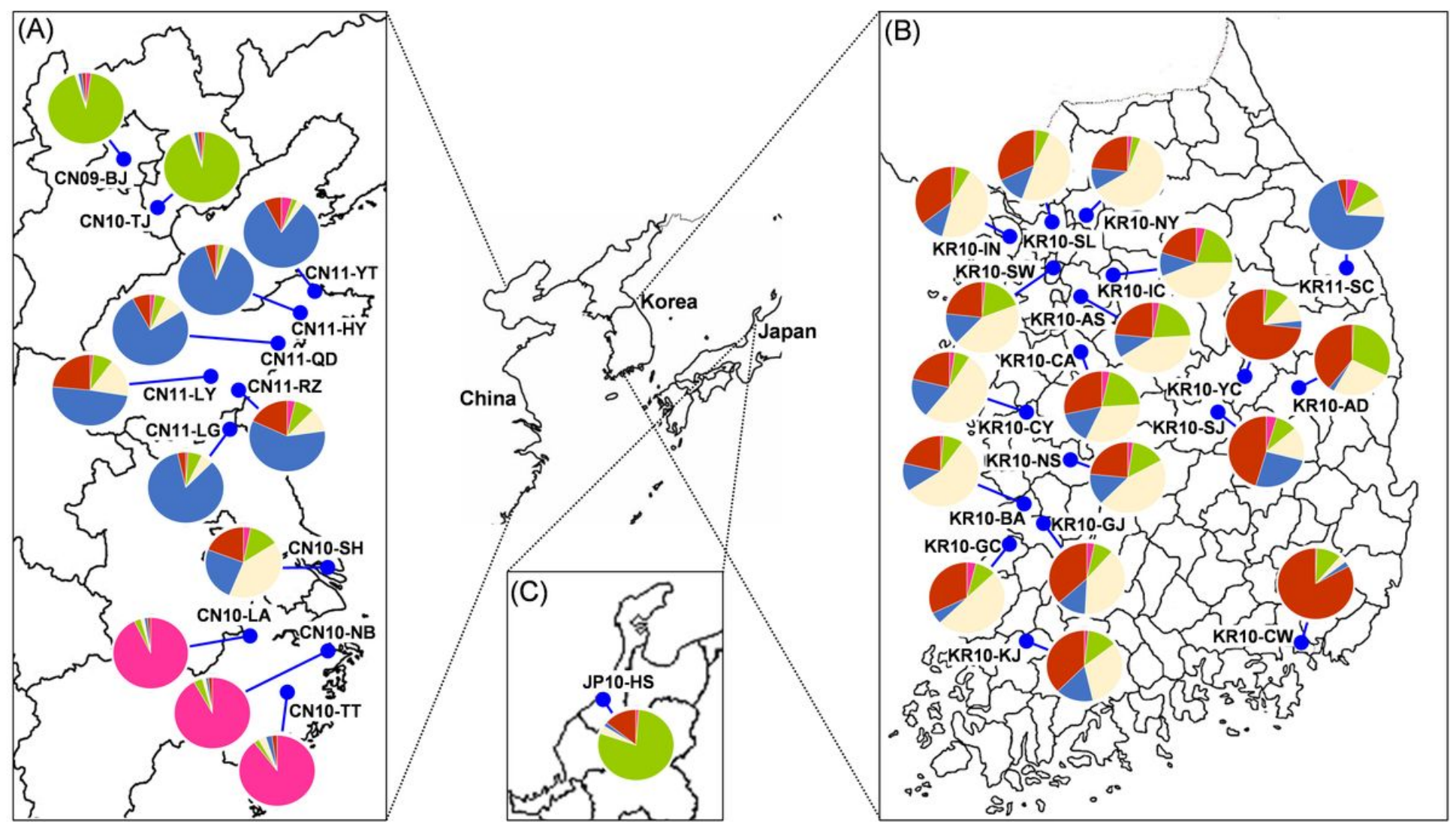

Figure 3

Sampling locations for 31 populations of SLF in (A) China (12 populations), (B) Korea (18 populations) and (C) Japan (1 population). The pie graphs indicate the genetic structure of each local population based 
on a Bayesian inference of multilocus microsatellite genotype in STRUCTURE, which is partitioned when $\mathrm{K}$ $=5$. Note: The designations employed and the presentation of the material on this map do not imply the expression of any opinion whatsoever on the part of Research Square concerning the legal status of any country, territory, city or area or of its authorities, or concerning the delimitation of its frontiers or boundaries. This map has been provided by the authors.
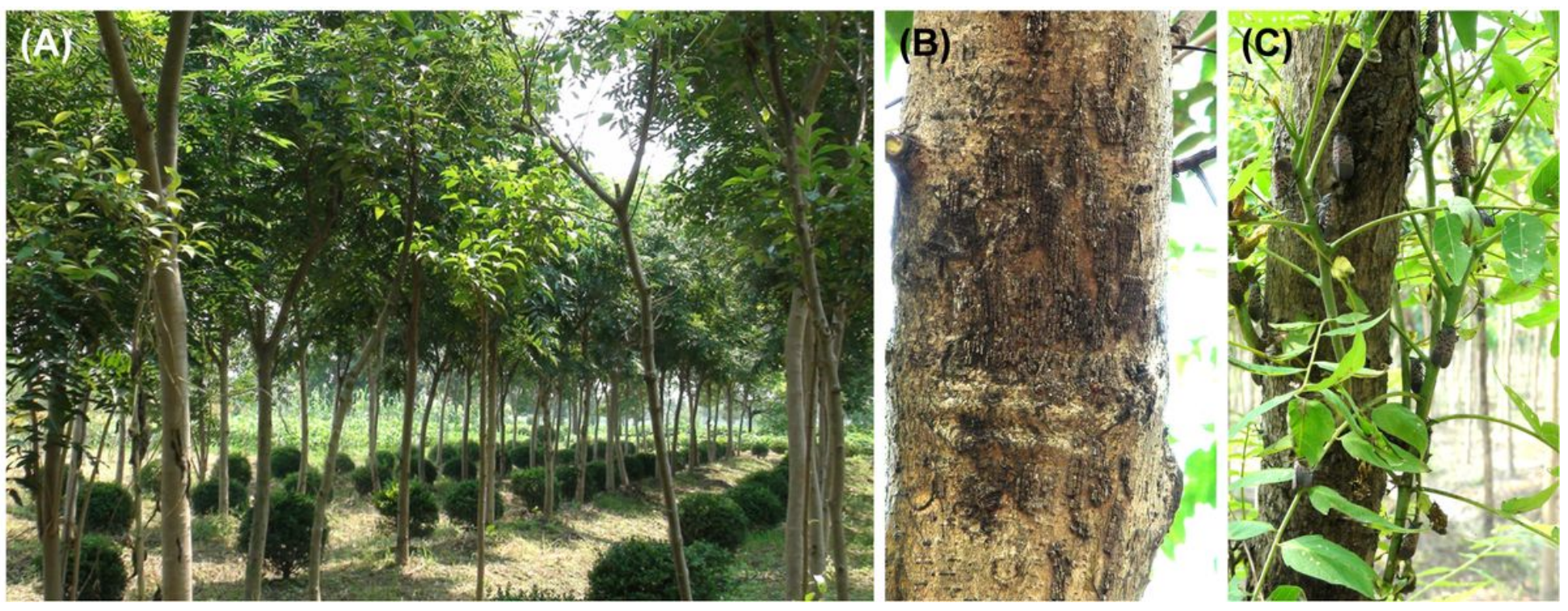

\section{Figure 4}

Photographs of a collection site of CN10-SH as strongly inferred to the main source area; (A) planted density of the host plants (A. alitissima), (B) egg masses on a tree bark, (C) large number of SLF adults on a tree

\section{Supplementary Files}

This is a list of supplementary files associated with this preprint. Click to download.

- Supplementarymaterial1Figs.S1S6.docx

- Supplementarymaterial2TablesS1S3.docx 